\title{
TRIGONAL ICE CRYSTALS IN EARTH'S ATMOSPHERE
}

\author{
by Benjamin J. Murray, Christoph G. Salzmann, Andrew J. Heymsfield, Steven Dobbie, \\ Ryan R. Neely III, and Christopher J. Cox
}

Ice crystals with threefold symmetry in the atmosphere may not be made of hexagonal ice.

s n late 1611, Johannes Kepler was pondering what he should give his friend and patron, Baron Wackher von Wackhenfels, as a New Year's gift when a snowflake landed on his coat. He was struck with a perfect philosophical present for his patron: why do snowflakes have six corners rather than some other number, say, seven or five? In the pamphlet that Kepler produced as a gift for his friend, he presented the first discussion of the connection between the hexagonal symmetry of snowflakes and the most efficient way of stacking spheres. He used the practical problem of how to best stack cannonballs on a ship as an analogy where each successive layer is positioned at the lowest point you can find in the preceding layer (Ball 2011; Kepler 2010).

Kepler's ideas only became testable with the advent of crystallography in the early twentieth century. While X-ray diffraction showed that the structure of ice is more complicated than the stacking of cannonballs, it also became clear that Kepler's suggestion that the hexagonal symmetry of snowflakes was related to the arrangement of the smallest building blocks of matter was correct (Hobbs 1974). Hence, it comes as a surprise that ice crystals can display threefold rotational symmetry rather than the sixfold symmetry associated with hexagonal ice. Many of these crystals are observed under conditions we normally associate with standard hexagonal ice, but the symmetry of these crystals suggests that the structure of ice under common atmospheric conditions is not consistent with that of hexagonal ice.
In this paper, we first review images of crystals with threefold rotational symmetry as well as present new images from Summit in Greenland. We review the geographical locations where threefold symmetry has been documented in the literature and then summarize the results of recent laboratory experiments in the ice physics and chemistry community concerning the crystal structure of ice. We use these results to predict crystal shape and show that stacking disorder in ice can lead to threefold symmetry in ice crystals. Finally, we discuss the implications of trigonal ice crystals for atmospheric halos and radiative properties of clouds.

\section{ATMOSPHERIC ICE CRYSTALS WITH} THREEFOLD ROTATIONAL SYMMETRY. We present examples of observed atmospheric ice crystals with threefold symmetry in Figs. 1-3 and summarize observations of crystals with threefold symmetry from the wider literature in Table 1 . Threefold symmetry can be seen if a crystal is rotated $360^{\circ}$ about its center and the shape of the crystal "matches" the initial shape three times. Figure 1 shows images from the tropical tropopause layer (TTL), which is the coldest place in the troposphere or stratosphere and is a region where clouds influence water transport into the stratosphere (Jensen et al. 2013; Murray et al. 2005; Peter et al. 2006). These crystals were sampled by Heymsfield (1986) in the equatorial Pacific TTL near $16.5 \mathrm{~km}$ from about $-83^{\circ}$ to $-84^{\circ} \mathrm{C}$. Approximately $50 \%$ of the 
5-50- $\mu \mathrm{m}$ crystals sampled had threefold symmetry and most of the other crystals sampled were columns of unknown symmetry (Heymsfield 1986).

Lawson et al. (2008) report that crystals with threefold symmetry were present in the TTL but were rare, and that ice crystals were sometimes larger than $100 \mu \mathrm{m}$ in contrast to the smaller-than-50- $\mu \mathrm{m}$ size reported by Heymsfield (1986). Lawson et al. (2008) used a cloud particle imager (CPI), which only resolves the shape of particles larger than $30 \mu \mathrm{m}$, whereas Heymsfield used a Formvar replicator technique that has much better resolution. Hence, it is possible that crystals with threefold symmetry are dominantly in a size range where the CPI is insensitive. Similar to Heymsfield (1986), Yamashita (1973) found that crystals with threefold symmetry were typically small (roughly less than $40 \mu \mathrm{m}$ on the basal face), so it is possible that the incompletely resolved smaller ice crystals reported by Lawson et al. (2008) included crystals with threefold symmetry. More in situ measurements are needed in the TTL with techniques sensitive to the full range of particle sizes.

New images of ice crystals collected at ground level at Summit, Greenland $\left(72.6^{\circ} \mathrm{N}, 38.5^{\circ} \mathrm{W}, 3216 \mathrm{~m}\right.$

AFFILIATIONS: MuRRAY AND DOBBIE-Institute for Climate and Atmospheric Science, School of Earth and Environment, University of Leeds, Leeds, United Kingdom; SALZMANN-Department of Chemistry, University College London, London, United Kingdom; HeYmsfield-National Center for Atmospheric Research, Boulder, Colorado; NeElY - Institute for Climate and Atmospheric Science, School of Earth and Environment, University of Leeds, Leeds, United Kingdom, and National Center for Atmospheric Research, and Cooperative Institute for Research in Environmental Sciences, and NOAA/Earth System Research Laboratory, Boulder, Colorado; Cox-Cooperative Institute for Research in Environmental Sciences, and NOAA/Earth System Research Laboratory, and Department of Atmospheric and Oceanic Sciences, University of Colorado Boulder, Boulder, Colorado

CORRESPONDING AUTHOR: Benjamin J. Murray, Institute for Climate and Atmospheric Science, School of Earth and Environment, University of Leeds, Woodhouse Lane, Leeds LS2 9JT, United Kingdom

E-mail: b.j.murray@leeds.ac.uk; c.salzmann@ucl.ac.uk

The abstract for this article can be found in this issue, following the table of contents.

DOI:10.1175/BAMS-D-13-00128.I

A supplement to this article is available online (I0.II75/BAMS-D-13-00128.2)

In final form II October 2014

@2015 American Meteorological Society

This article is licensed under a Creative Commons Attribution 4.0 license.
MSL) from 2010 through 2013 are shown in Fig. 2. Ice crystals with threefold symmetry are observed throughout the entire year and were typically observed when the surface temperature was between $-5^{\circ}$ and $-40^{\circ} \mathrm{C}$. The temperature where the crystals originated is unknown, and observations during collection times suggest a variety of atmospheric conditions, but there was a preference for trigonal crystals at lower temperatures. Ice crystals like these are often associated with diamond dust, which can produce atmospheric halos (Tape 1994). The plate crystals with threefold symmetry in Fig. 2 were sampled together with plates of sixfold symmetry, columns, and other crystal shapes. Crystals with threefold rotational symmetry have also been observed in other locations where diamond dust forms, such as Antarctica (Kikuchi and Hogan 1979; Satow 1983; Tape 1994).

The earliest photographs of crystals with threefold symmetry that we know of were recorded by Bentley in Vermont (Bentley and Humphreys 1962). A selection of these images, taken between 1885 and 1931, is reproduced in Fig. 3. More recently, Libbrecht (2006, 2008) also published images of snowflakes with threefold symmetry.

Columns with threefold rotational symmetry are sometimes observed in the atmosphere (Tape and Moilanen 2006) and the laboratory (Yamashita 1969, 1971, 1973). Examples from Tape and Moilanen (2006) of columns with threefold symmetry when viewed from the basal face are shown in Fig. 4 . When plate crystals are sampled, they tend to orientate with their basal faces pointing upward (i.e., in the optimal plane to be imaged), whereas columns tend to orientate with only their prismatic faces visible. Therefore, threefold symmetry in plates is more commonly photographed but not necessarily more common in the atmosphere.

In addition to the examples illustrated in Figs. 1-3, there are a number of other observations of ice crystals with threefold symmetry summarized in Table 1 and Fig. 5. In summary, ice crystals with threefold symmetry are observed all around the globe, in many cloud types, and over a wide range of conditions. In some clouds they may be a minor component, but in others such as very cold TTL cirrus they may be a dominant class of ice crystals.

\section{THE CRYSTAL STRUCTURE OF ICE: STACKING FAULTS AND STACKING-} DISORDERED ICE I. To understand threefold rotational symmetry of single crystals of ice we need to appreciate the structure of ice I (pronounced "ice one"). Ice I has two well-defined crystalline forms: 
hexagonal ice (ice $\mathrm{I}_{\mathrm{h}}$ ) and hypothetical cubic ice (ice I ). Both phases are made up of identical layers of puckered six-membered rings of oxygen atoms connected with hydrogen bonds. However, the way these layers are stacked distinguishes ice $I_{h}$ and $I_{c}$. A side view of an individual layer of ice is shown in Fig. 6a. In ice $I_{h}$, the stable and common form of ice, each successive layer is the mirror image of the preceding layer, as depicted in Fig. 6b. In contrast, ice $\mathrm{I}_{c}$ is made up of the same layers shown in Fig. 6a, but each successive layer is shifted relative to the previous layer by one-half of the diameter of a hexagonal ring, resulting in the structure shown in Fig. 6c. The difference in stacking results in crystals with different symmetry in the crystal structure and different shapes of single ice crystals.

The existence and ubiquity of ice $I_{h}$ in nature is well established, but the same cannot be said for ice $I_{c}$. In recent years much of the ice labeled as ice $I_{c}$ in the literature has been shown to not actually have a cubic structure (Hansen et al. 2008a,b; Kuhs et al. 2012; Malkin et al. 2012, 2015). These studies have now shown that the ice thought to be purely ice $I_{c}$ is actually composed of both cubic and hexagonal sequences that are interlaced to produce a distinct type of ice (Kuhs et al. 2012; Malkin et al. 2012). An example of a possible structure for this ice is shown in Fig. 6d. Malkin et al. (2012) suggest calling this stacking-disordered ice (ice $\mathrm{I}_{\text {sd }}$ ) in order to distinguish it from the two well-defined forms of ice I (ice $I_{c}$ and $I_{h}$ ). Kuhs et al. (2012) suggest calling it "ice $I_{c}$ " where the quotation marks are intended to indicate that it is not actually cubic. In this paper we emphasize the fact that this material is neither cubic nor hexagonal, and therefore we refer to it as ice $\mathrm{I}_{\text {sd. }}$.

Stacking disorder can exist as intermittent faults in a crystal structure that is dominantly ice $I_{h}$ and in such a case we refer to the infrequent cubic sequences as stacking faults. The point at which ice $\mathrm{I}_{\mathrm{h}}$ with some faults becomes ice $I_{\text {sd }}$ is subjective, but it is practical to define ice $\mathrm{I}_{\mathrm{sd}}$ as having more than $1 \%$ of the minor sequence. This roughly corresponds to the point where an X-ray diffraction pattern of ice I with cubic stacking faults in a dominantly hexagonal structure would significantly deviate from the pattern of welldefined ice $I_{h}$ (Malkin et al. 2015).

THE SHAPES OF SINGLE CRYSTALS OF ICE $\mathbf{I}_{\text {sd }}$. In this section we ask the following: what is the shape (or habit) of an ice crystal that contains stacking disorder growing under isotropic conditions? The sidebar on "Crystallography and crystal shape" introduces the concept of crystallographic symmetry and how symmetry defines the shape of ice crystals. The hexagonal crystal structure of ice $I_{h}$ can manifest in hexagonal columns and plates (Figs. 7a and 7b), while the hypothetical ice I phase is predicted to form cubes, octahedra, or cubooctahedra (Figs. 7d-f). In contrast to cubic and hexagonal ice, we find that ice with stacking disorder is characterized by a trigonal crystal structure and we expect crystals with threefold symmetry (Figs. $7 \mathrm{~g}-\mathrm{i}$ ) (see sidebar). Hallett et al. (2002) also recognized that introduction of cubic sequences to a hexagonal structure would result in threefold rotational symmetry. Crystals in the trigonal and hexagonal crystal
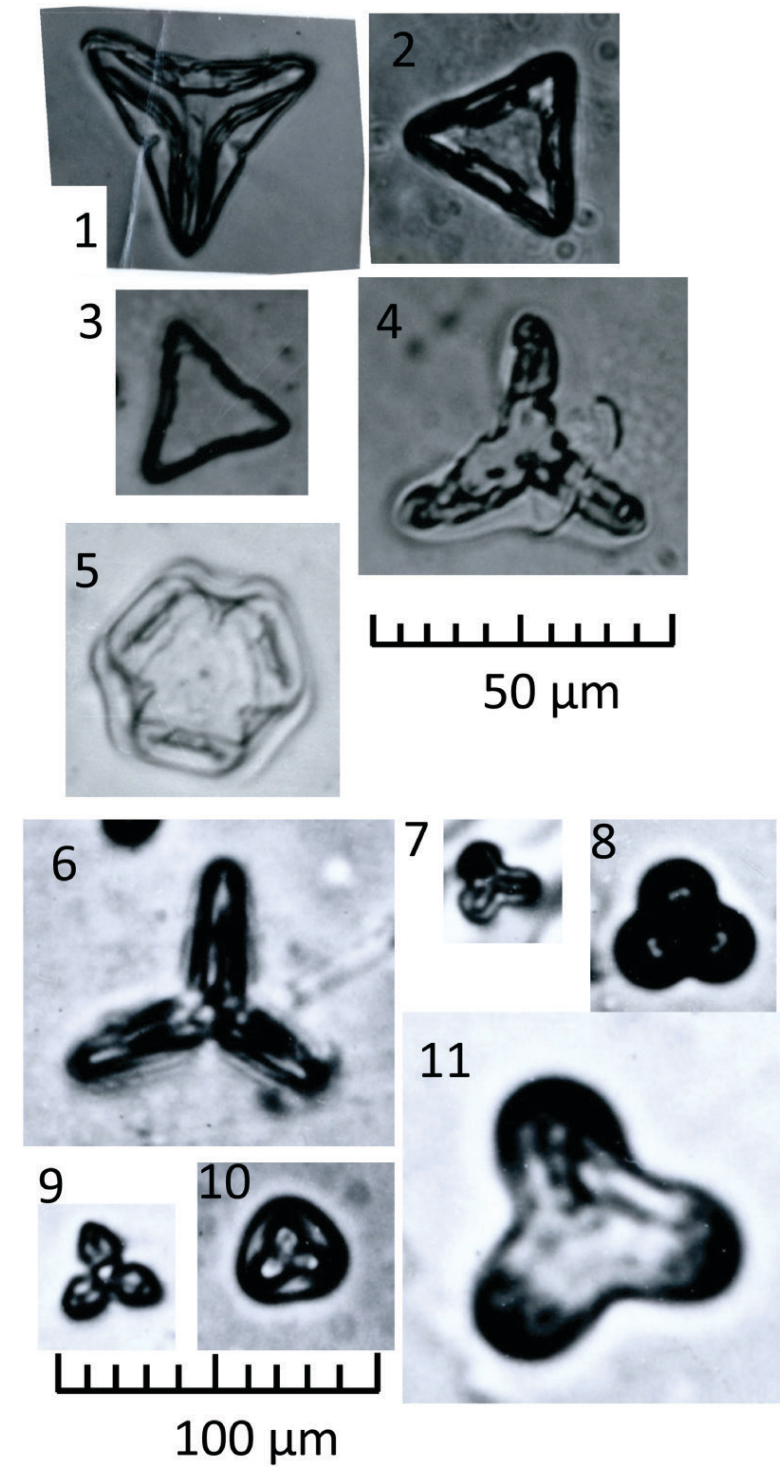

FIG. I. Ice crystals with threefold symmetry sampled in the tropical tropopause layer. Formvar replica ice crystal is sampled from an aircraft at 16.2-16.7 km in Dec 1973 , where the temperature was about $-84^{\circ}$ to $-83^{\circ} \mathrm{C}$. 


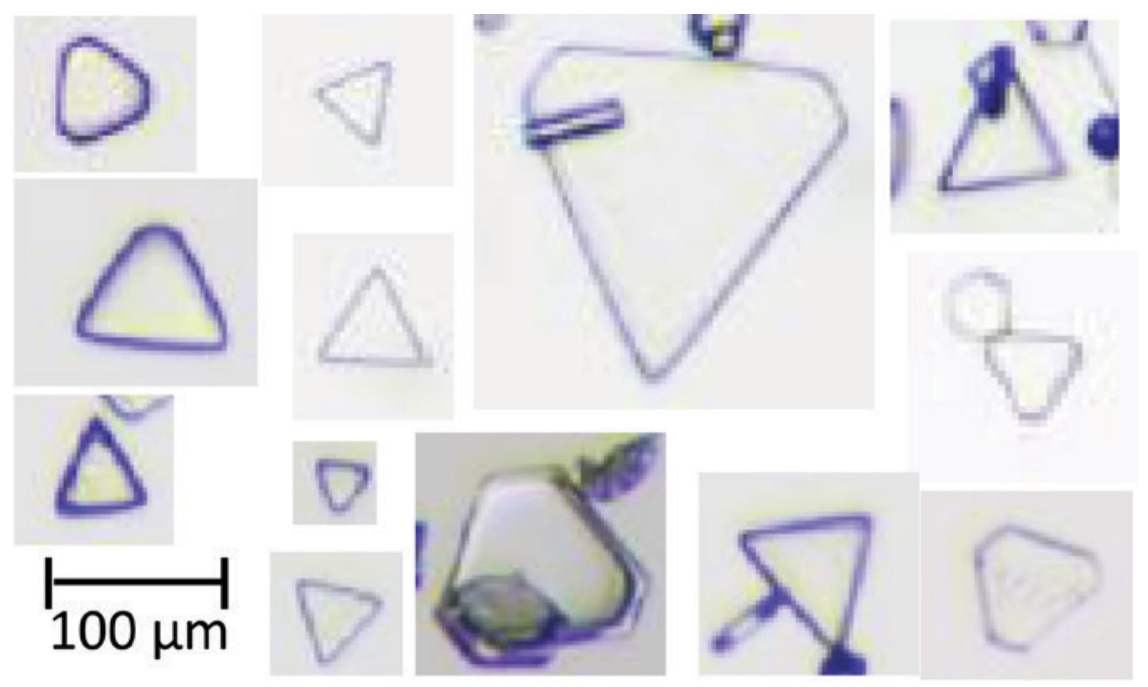

an equilateral-triangular shape (Fig. 7i). Similar to ice $I_{h}$ crystals, ice $I_{\text {sd }}$ crystals can appear as plates or columns depending on the relative growth rates of the basal and prismatic faces. The crystals with threefold symmetry in Figs. 1-4 are consistent with trigonal symmetry in the crystal structure and we therefore use the term trigonal ice crystals when referring to these crystals.

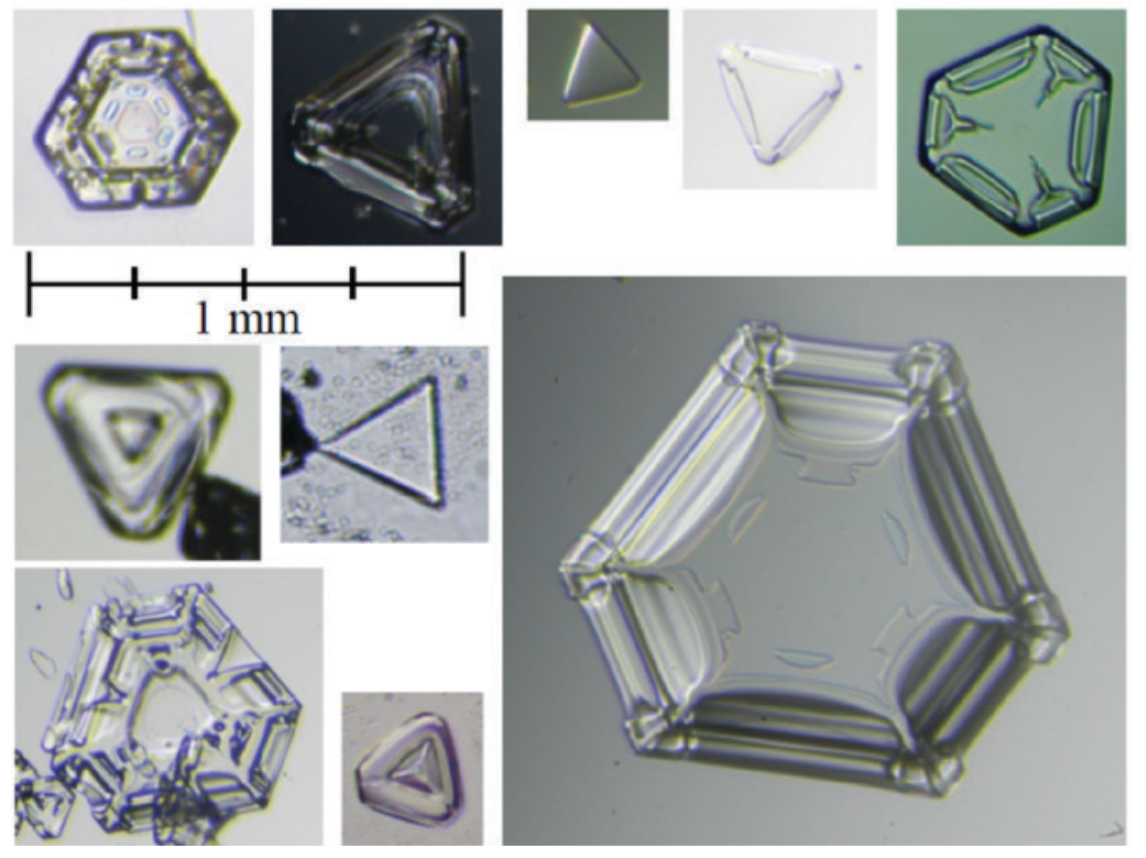

FIG. 2. Ice crystals with threefold symmetry from Summit, Greenland. Crystals were sampled manually using cold slides and a microscope in the Integrated Characterization of Energy, Clouds, Atmospheric State and Precipitation at Summit (ICECAPS) project, Greenland (3216 m MSL) (Shupe et al. 2013).

\section{LABORATORY WORK ON STACKING DIS- ORDER IN ICE. Re-} cent work has shown that stacking disorder in ice I, especially during the early stages of crystallization, is much more significant than previously thought. Malkin et al. (2012) demonstrated that approximately $1-\mu \mathrm{m}$ water droplets, which froze homogeneously at around $-40^{\circ} \mathrm{C}$, crystallized to ice $\mathrm{I}_{\text {sd }}$ with perfectly random stacking disorder $(50 \%$ of the stacking was cubic and $50 \%$ was hexagonal). In addition, Malkin et al. (2015) show that droplets that froze at temperatures up to $-15^{\circ} \mathrm{C}$ contained stacking disorder and suggested that the initial ice to crystallize when water freezes is always stackingsystems are closely related and crystals of ice $\mathrm{I}_{\text {sd }}$ can have six prismatic faces. However, in ice $\mathrm{I}_{\text {sd }}$ the crystal symmetry dictates that two sets of alternating faces are symmetry independent (Fig. $7 \mathrm{~g}$ ). If these two groups of faces grow at the same rate, then the basal face will be hexagonal, whereas if they grow at different rates, then the basal face will be a scalene with threefold symmetry (Figs. $7 \mathrm{~g}$,h). In the case where the growth rates of one set of faces is much faster than the others, the basal face will take on disordered ice but that the disorder can anneal at warmer temperatures, through rearrangements of the crystal lattice, to yield pristine ice $\mathrm{I}_{\mathrm{h}}$. It is known that stacking disorder anneals out more rapidly at warmer temperatures (Hansen et al. 2008b; Murray and Bertram 2006). Hence, the transient presence of stacking disorder in ice may influence crystal shapes over a very wide range of temperatures. This is consistent with observations of ice with threefold rotational symmetry over a wide range of temperatures in the 


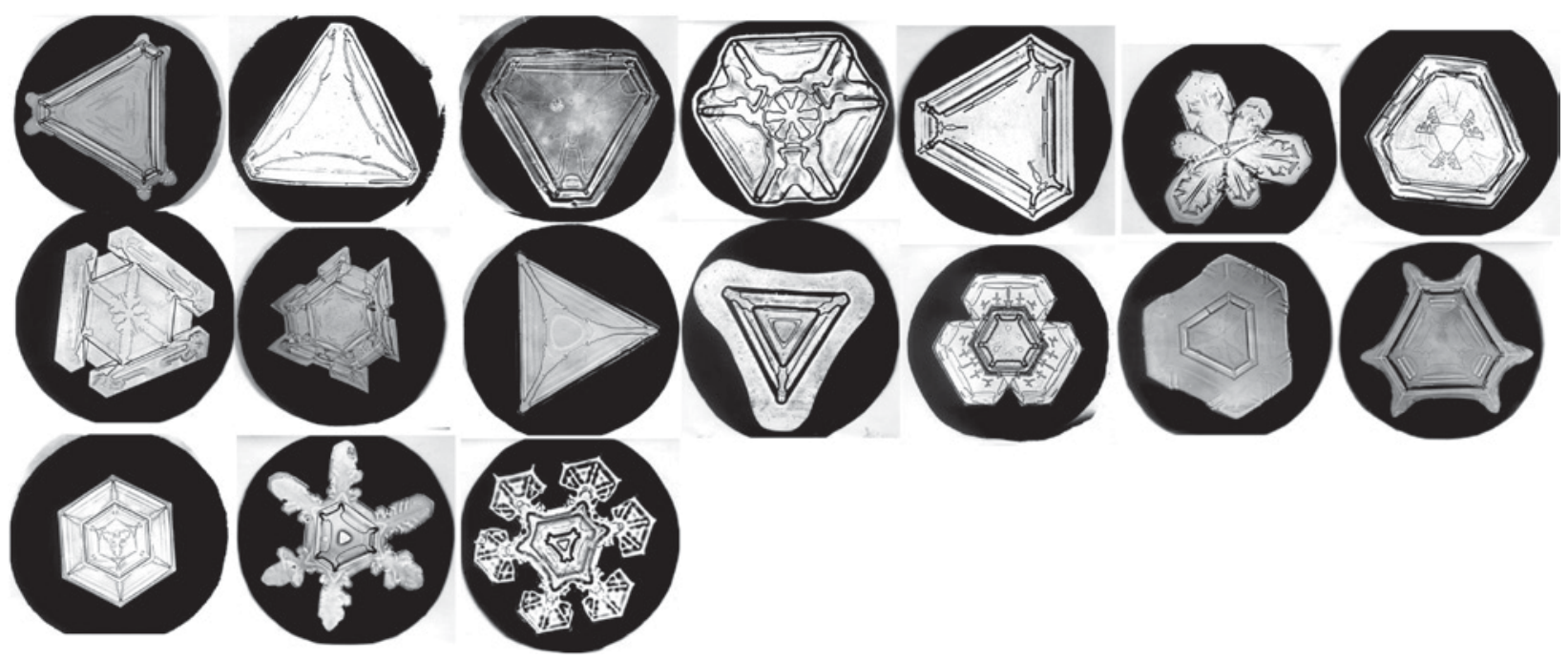

FIG. 3. Photographs of a variety of ice crystals displaying threefold symmetry taken by Bentley in the period between 1885 and 193I. [Photo credit: Wilson Bentley Digital Archives of the Jericho Historical Society: www.snowflakebentley.com].

atmosphere. Kuhs et al. (2012) present electronmicroscope images of scalene hexagonal columns with threefold symmetry that also have kinks on the prismatic faces, which they attribute to stacking faults. X-ray techniques have also been used to show stacking faults were present in vapor-grown ice crystals at temperatures as warm as $-3^{\circ} \mathrm{C}$ (McKnight and Hallett 1978; Mizuno 1978). The available experimental evidence therefore suggests that stacking disorder is an inherent feature of ice grown under a wide range of atmospheric conditions and could explain the occurrence of ice crystals with threefold symmetry in the atmosphere.

\section{THE GROWTH OF ICE CRYSTALS: EVO-} LUTION FROM THREE- TO SIXFOLD ROTATIONAL SYMMETRY. A number of crystals in Fig. 3 whose outer edges are close to defining a perfect hexagon shape have internal markings with threefold rotational symmetry. Inspection of many of the crystals presented by Libbrecht $(2006,2008)$ also shows markings at their center with threefold symmetry. Does this indicate that the early stages of these hexagonal crystals were in fact trigonal? This is consistent with the X-ray-diffraction studies of frozen droplets mentioned above (Malkin et al. 2012, 2015). Yamashita (1973) also presented evidence that many crystals in their experiments began as triangular crystals evolving first into scalene hexagons and then into hexagonal crystals as they grew. At temperatures between $-5^{\circ}$ and $-8^{\circ} \mathrm{C}$, Yamashita (1973) used adiabatic expansion to generate an ice cloud that consisted of $10 \%-19 \%$ trigonal crystals and a further $37 \%-82 \%$ were scalene hexagons (30\%-64\% were scalenes with threefold symmetry). They then took these ice crystals, many of which were trigonal columns, and exposed them to conditions favoring plate growth. They present images of the resulting crystals that were made up of trigonal columns with scalene or hexagonal plates on either end.

Many studies show that stacking disorder in ice is not energetically favorable and can anneal out in time (Hansen et al. 2008b; Kuhs et al. 2012; Murray and Bertram 2006). After holding a sample of ice at $-30^{\circ} \mathrm{C}$, Murray and Bertram (2006) show that stacking disorder was still present after several hours, but at $-10^{\circ} \mathrm{C}$ the stacking disorder annealed out much more readily. Hence, one might expect trigonal crystals to be more common at lower temperatures. This seems to be true at $-80^{\circ} \mathrm{C}$ in the tropical tropopause (Fig. 1), where $50 \%$ of crystals had threefold symmetry, but the trend is less clear at warmer temperatures. By seeding ice in a supercooled cloud by adiabatic expansion, Yamashita (1973) showed that in crystals grown at around $-15^{\circ} \mathrm{C}$ no trigonal or scalene hexagons formed out of 50 observed crystals; whereas at $-7^{\circ} \mathrm{C}, 69 \%$ of the 109 observed crystals had threefold symmetry [seeding using dry ice resulted in a similar trend (Yamashita 1973)]. In ice crystals seeded with dry ice in a supercooled cloud at $-5^{\circ} \mathrm{C}$, Yamashita (1969) found that $20 \%$ of crystals were trigonal columns and $6 \%$ were what he termed trigonal pyramids. Libbrecht and Arnold (2014) found that approximately $5 \%$ of crystals grown at $-10^{\circ} \mathrm{C}$ at a supersaturation of $1.4 \%$ had threefold symmetry. Clearly, establishing the temperature ranges and 


\begin{tabular}{|c|c|c|c|c|c|}
\hline Location & Cloud type & $\begin{array}{c}\text { Cloud } \\
\text { height }(\mathrm{km})\end{array}$ & Temperature (C) & Reference & Notes \\
\hline Marshall Islands & TTL & 16.5 & $-83^{\circ}$ to $-84^{\circ}$ & $\begin{array}{l}\text { Heymsfield } \\
\text { (1986) }\end{array}$ & $\begin{array}{l}50 \% \text { of the } \\
5-50-\mu \mathrm{m} \text { crystals } \\
\text { sampled had } \\
\text { threefold sym- } \\
\text { metry. }\end{array}$ \\
\hline $\begin{array}{l}\text { San Jose, } \\
\text { Costa Rica }\end{array}$ & TTL & 16.2 to 17.7 & $-75^{\circ}$ to $-90^{\circ}$ & $\begin{array}{l}\text { Lawson et al. } \\
(2008)\end{array}$ & $\begin{array}{l}\text { Threefold sym- } \\
\text { metry present but } \\
\text { rare. Some crys- } \\
\text { tals }>100 \mu \mathrm{m} \text {. }\end{array}$ \\
\hline South Pole & Diamond dust & - & - & Tape (1994) & \\
\hline $\begin{array}{l}\text { Fairbanks, } \\
\text { Alaska }\end{array}$ & Diamond dust & - & - & Tape (1994) & \\
\hline South Pole & Diamond dust & - & $-35^{\circ}$ & $\begin{array}{l}\text { Kikuchi and } \\
\text { Hogan (1979) }\end{array}$ & \\
\hline $\begin{array}{l}\text { Mizuho Plateau, } \\
\text { Antarctica }\end{array}$ & $\begin{array}{l}\text { Precipitation col- } \\
\text { lected at surface }\end{array}$ & - & $-38^{\circ}$ to $-43^{\circ}$ & Satow (1983) & \\
\hline $\begin{array}{l}\text { Jericho, Ver- } \\
\text { mont }\end{array}$ & $\begin{array}{l}\text { Precipitation col- } \\
\text { lected at surface }\end{array}$ & - & - & $\begin{array}{l}\text { Bentley and } \\
\text { Humphreys } \\
\text { (1962) }\end{array}$ & $\begin{array}{l}\text { Earliest photo- } \\
\text { graphs of three- } \\
\text { fold symmetry. }\end{array}$ \\
\hline Michigan & $\begin{array}{l}\text { Precipitation col- } \\
\text { lected at surface }\end{array}$ & - & $-8^{\circ}$ to $-18^{\circ}$ & $\begin{array}{l}\text { Libbrecht } \\
(2006 ; 2008)\end{array}$ & \\
\hline Kansas & $\begin{array}{l}\text { Frontal cirrus } \\
\text { cloud }\end{array}$ & - & $-63^{\circ}$ & $\begin{array}{l}\text { Hallett et al. } \\
(2002)\end{array}$ & \\
\hline Western Pacific & $\begin{array}{l}\text { Deep tropical } \\
\text { convection }\end{array}$ & - & $-48^{\circ}$ & $\begin{array}{l}\text { Hallett et al. } \\
(2002)\end{array}$ & \\
\hline Alps & Cirrus & - & $-55^{\circ}$ & $\begin{array}{l}\text { Hallett et al. } \\
(2002)\end{array}$ & \\
\hline- & $\begin{array}{l}\text { Evaporating con- } \\
\text { trail }\end{array}$ & - & $-55^{\circ}$ & $\begin{array}{l}\text { Hallett et al. } \\
(2002)\end{array}$ & \\
\hline- & Tropical storm & 9 to 13 & - & $\begin{array}{l}\text { Hallett et al. } \\
(2002)\end{array}$ & \\
\hline Oklahoma & Cirrus & 11.4 to 12.2 & $-43^{\circ}$ to $-49^{\circ}$ & $\begin{array}{l}\text { Sassen et al. } \\
(2003)\end{array}$ & $\begin{array}{l}\text { Associated with } \\
\text { Hurricane Nora } \\
1997 .\end{array}$ \\
\hline $\begin{array}{l}\text { Palmer Pennin- } \\
\text { sula, Antarctica }\end{array}$ & PSC & 12.5 to 16.5 & $-72^{\circ}$ to $-78^{\circ}$ & $\begin{array}{l}\text { Goodman } \\
\text { et al. (1989) }\end{array}$ & $\begin{array}{l}\text { Threefold sym- } \\
\text { metry in } 4 \% \text { of } \\
\text { observations. }\end{array}$ \\
\hline Arctic & Various & - & $-20^{\circ}$ to $-36^{\circ}$ & $\begin{array}{l}\text { Korolev et al. } \\
\text { (1999) }\end{array}$ & \\
\hline
\end{tabular}

supersaturations over which trigonal crystals form requires more work.

To explain the formation of trigonal crystals, Libbrecht and Arnold (2014) proposed that a random enhancement in growth of one face of a hexagonal plate leads to aerodynamic effects resulting in trigonal crystals. In contrast, Yamashita (1973) shows that trigonal crystals evolve into hexagonal crystals rather than the other way around. Also, Libbrecht and Arnold's (2014) aerodynamic explanation only works for horizontally orientated plates, whereas trigonal columns are also observed in nature and the laboratory (Tape and Moilanen 2006; Yamashita 1973) but tend to fall on their sides. Wood et al. (2001) suggest that screw dislocations on specific faces can influence crystal shape since these dislocations can enhance the 


\section{CRYSTALLOGRAPHY AND CRYSTAL SHAPE}

$\mathrm{T}^{\mathrm{s}}$ he collection of symmetry elements that describes the symmetry of a crystalline material is summarized by the crystallographic space group. It has been shown that ice $I_{h}$ has the space group $\mathrm{P}_{3} / \mathrm{mmc}$ in the hexagonal crystal system (Table SBI) (Hobbs 1974), where $P$ means that it has a primitive unit cell, $6_{3}$ indicates the presence of a sixfold screw axis (rotation around an axis in addition to a translation along the axis), $\mathrm{m}$ indicates a mirror plane (reflection), and $\mathrm{c}$ indicates glide planes (a translation and a reflection) (Hobbs 1974). Only the nontranslational symmetry elements are relevant for the shape of a macroscopic crystal and it is therefore useful to summarize these elements in the form of a point group. The point group can be determined by converting the translational symmetry elements into their equivalent nontranslational elements; that is, glide planes convert to mirror planes and screw axes convert to rotational axes. The space group of ice $\mathrm{I}_{\mathrm{h}}, \mathrm{P} 6_{3} / \mathrm{mmc}$, converts to the crystallographic point group 6/mmm (Dent Glasser 1984), which defines sixfold rotational symmetry in a macroscopic crystal (see Fig. 7).

No experimental $x$-ray diffraction pattern exists for welldefined ice $I_{c}$, but this hypothetical material is isostructural with cubic diamond (Kuhs et al. 1987; Pruppacher and Klett 1997). Its space group is $F d \overline{3} \mathrm{~m}$, where the $F$ indicates a facecentered unit cell, $d$ is a special type of glide plane, $\overline{3}$ shows that there is a threefold rotoinversion axis, and $m$ indicates mirror planes. This space group is in the cubic crystal system. The corresponding point group is $m \overline{3} \mathrm{~m}$, which is the octahedral point group (Table SBI).

Stacking-disordered ice has an x-ray diffraction pattern distinct from the calculated patterns of both ice $I_{c}$ and ice $I_{h}$ and includes broad and asymmetric features from the stacking disorder (Kuhs et al. 20I2; Malkin et al. 20I2, 20I5). To identify the space group symmetry of ice $\mathrm{I}_{\text {sd }}$, a unit cell containing a large number of randomly stacked layers was constructed. We identify the space group symmetry of the structure as the trigonal space group $\mathrm{P} 3 \mathrm{ml}$ using the findsym program (Stokes and Hatch 2005), consistent with the conclusions of Hansen et al. (2008a) and Kuhs et al. (2012). The crystallographic point group of $\mathrm{P} 3 \mathrm{ml}$ is $3 \mathrm{ml}$ (Table SBI) and indicates that crystals made of ice $I_{\text {sd }}$ will have threefold rotational symmetry.

The shape of a crystal is dictated by a combination of the symmetry defined by the point group and the relative rates of growth of different crystal faces. Miller indices are used to distinguish between different faces and have the form (hkl). Faces with high Miller indices are less energetically stable and crystals generally tend to take on shapes in which faces with lower Miller indices are exposed. For ice $I_{h}$, for example, the faces with the lowest Miller indices are the basal $[(00 \mathrm{I})$ and $(00 \overline{\mathrm{I}})]$ and prismatic faces $[(\mathrm{I00}),(\overline{\mathrm{I}} 00)$, (0I0), (0IO), (00I), and $(00 \overline{\mathrm{I}})]$, which form hexagonal plates and columns (Figs. 7a and $7 \mathrm{~b}$ ).

TABLE SBI. Crystallographic details of ice I.

\begin{tabular}{|c|c|c|c|c|}
\hline & Space group ${ }^{a}$ & $\begin{array}{c}\text { Point group } \\
\text { (Hermann-Mauguin } \\
\text { notation) }\end{array}$ & $\begin{array}{c}\text { Point group }{ }^{\mathrm{b}} \\
\text { (Schönflies notation) }\end{array}$ & $\begin{array}{l}\text { Crystal } \\
\text { system }^{c}\end{array}$ \\
\hline Hexagonal ice (ice $I_{h}$ ) & $\mathrm{P}_{3} / \mathrm{mmc}(\# 194)$ & $6 / \mathrm{mmm}$ & $D_{6 h}$ & Hexagonal \\
\hline Cubic ice (ice $I_{c}$ ) & $\mathrm{Fd} \overline{3} \mathrm{~m}(\# 227)$ & $\mathrm{m} \overline{3} \mathrm{~m}$ & $O_{h}$ & Cubic \\
\hline $\begin{array}{l}\text { Stacking-disordered ice } \\
\left(\text { ice } I_{s d}\right)\end{array}$ & P3ml (\#156) & $3 m l$ & $C_{3 v}$ & Trigonal \\
\hline
\end{tabular}

a The space group describes all the symmetry elements of a crystal lattice.

${ }^{\mathrm{b}}$ The point group defines the subset of symmetry elements associated with an object - in this case, a macroscopic crystal. We list the point group in both of the commonly used notations.

${ }^{c}$ There are seven possible crystal systems, each of which defines a class of point groups.

growth rates of those faces. They suggest that screw dislocations on three alternate crystal faces might cause these faces to grow rapidly, yielding a crystal with threefold symmetry. In order for this explanation to work, the dislocations on each face would have to appear at the same time and influence growth in exactly the same way on all three faces. In summary, there are several mechanisms that could produce trigonal ice crystals in the atmosphere and it may be that all these mechanisms play a role in determining ice crystal shape; more work in this area is clearly needed.

\section{ATMOSPHERIC HALOS AND RADIATIVE PROPERTIES OF TRIGONAL ICE CRYS-}

TALS. Ice crystals with smooth faces give rise to dramatic and beautiful halo displays in Earth's atmosphere (Tape 1994; Tape and Moilanen 2006). Randomly orientated hexagonal crystals produce 


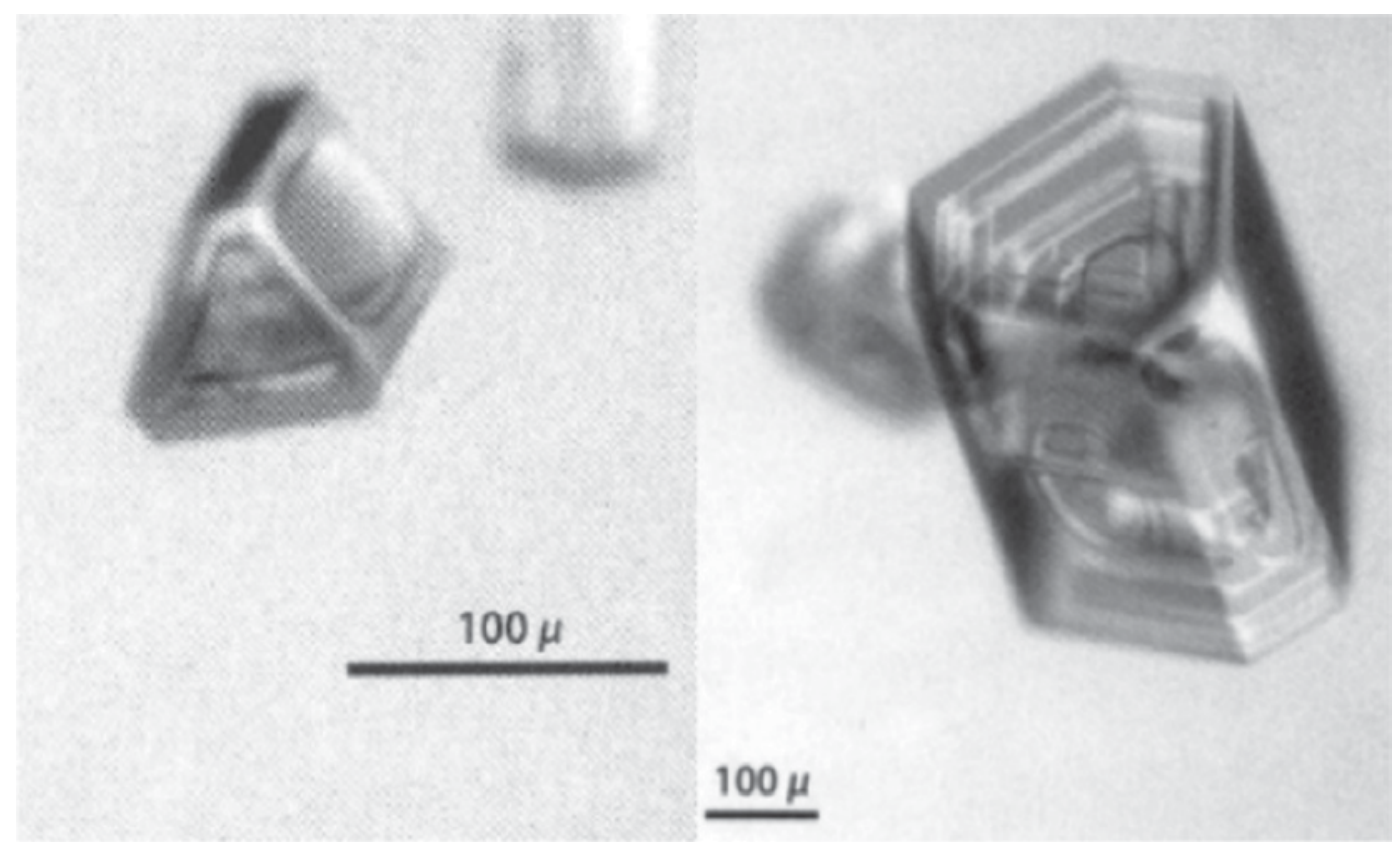

Fig. 4. Images of columns with threefold symmetry. These crystals happen to have settled in such a way that we can see both the prismatic and basal faces and therefore observe threefold symmetry on the basal face. [Reproduced from Tape and Moilanen 2006].

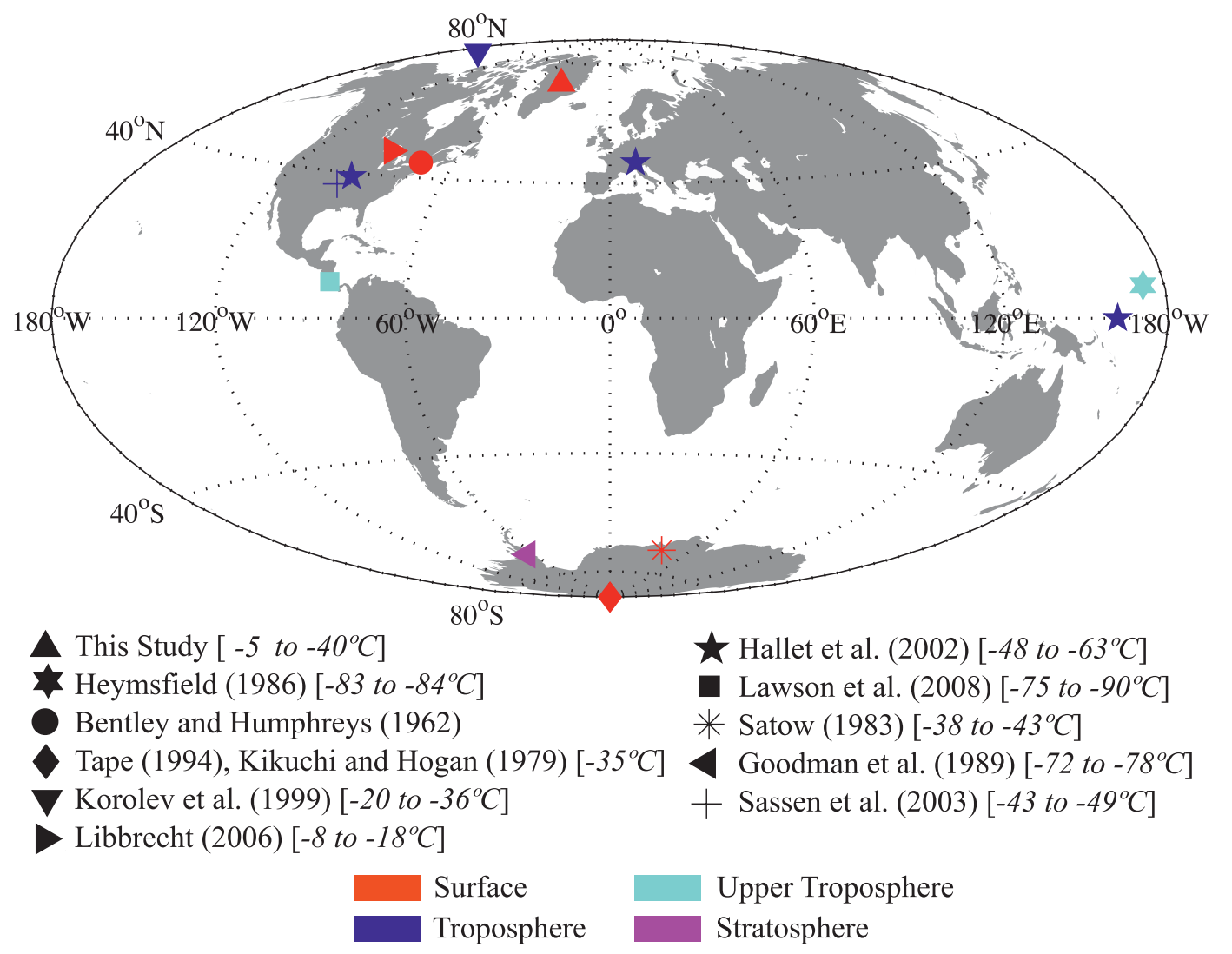

FIG. 5. Global map summarizing the locations of observations of ice crystals with threefold symmetry. 
common circular halos around the sun, whereas the preferred orientation of crystals leads to phenomena such as sundogs or the brightly colored circumzenith arc (Hobbs 1974). There are also a multitude of other halos and arcs that are much rarer, but in favorable conditions can produce dramatic displays filling the whole sky (Tape 1994).

One particular group of halos has been associated with hexagonal columns that fall with two prismatic faces horizontal. This is known as the Parry orientation after the explorer who, on searching for the Northwest Passage, became trapped in the Arctic sea ice, giving him the opportunity to study halos. Despite there being photographic evidence that halos associated with the Parry orientation exist, there is a controversy over how falling crystals could adopt this orientation since hexagonal columns fall with two prismatic faces vertical. In the past, it has been suggested that tabular ice crystals (hexagonal columns with two opposite prismatic faces much longer than the others) might give rise to Parry arcs and other associated halos. But, Tape (1994) showed the presence of Parry arcs is possible in the absence of any such crystals. Sassen and Takano (2000) suggested that thick-plate crystals could account for observed lidar depolarization ratios but could only generate the Parry arc if an aerodynamic stabilization force was invoked.

More recently, Westbrook (2011) demonstrated that scalene hexagonal columns orientate with two prismatic faces horizontal (i.e., in the Parry orientation). Hence, trigonal columns can fall in such a manner as to produce the unique Parry arc halo. This is consistent with our recent observations at Summit, Greenland, where we observed a Parry arc (see the halo in Fig. 8) close in time when we collected the trigonal ice crystals shown in Fig. 2. Tape (1994) also presents several cases of the Parry arc, from the South Pole, where simultaneously collected ice crystals were scalene. In summary, the results presented here suggest that stacking disorder in crystals can influence crystal shape and therefore orientation, which gives rise to the Parry arc.

The shape of ice crystals is important for their radiative properties and we now explore if trigonal columns have significantly different radiative properties compared to hexagonal columns. Accurately calculating the optical properties for nonspherical ice crystals based on the exact electromagnetic equations (Havemann and Baran 2001; Mishchenko et al. 1996; Sun et al. 1999) is possible but computationally very time consuming. In this work we use the anomalous diffraction approximation (ADA), originally proposed by van de Hulst (1957). We specifically investigate the optical properties of crystals of various sizes that range from trigonal columns with triangular basal faces through scalene columns to hexagonal columns. The intention is to shed light on whether clouds containing such particles are likely to have altered radiative properties. For details of the derivation of the extinction properties using the ADA method, please see the supplemental information (http://dx.doi.org/I0.II75/BAMS-D-I3-00 I28.2).

\section{(a) layer of water ice}

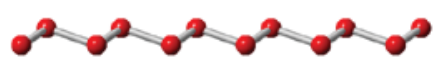

(b) hexagonal

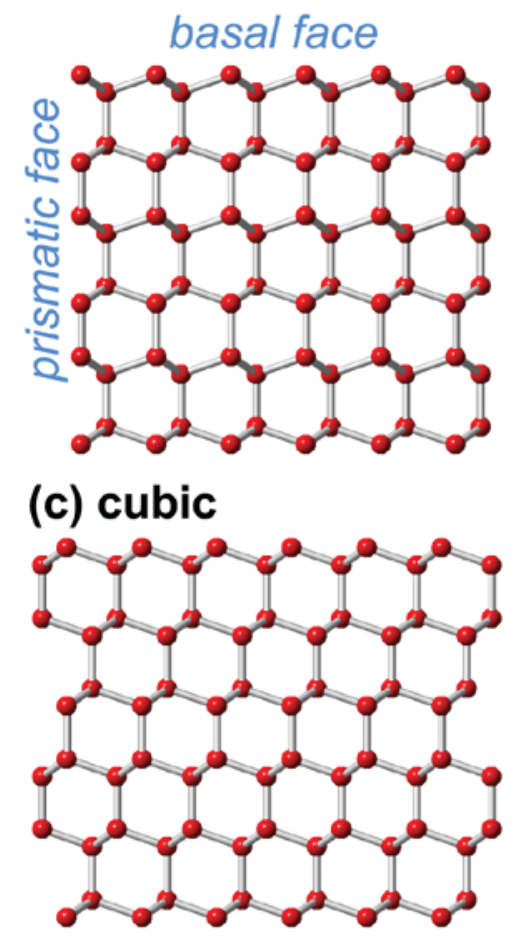

(d) Stacking disordered

Fig. 6. The crystal structures of hexagonal, cubic, and stacking-disordered ice. The red spheres indicate oxygen atoms, which are connected by hydrogen bonds where hydrogen atoms are omitted for clarity. 
(a)

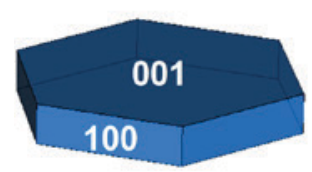

(b)

(e)

(h)

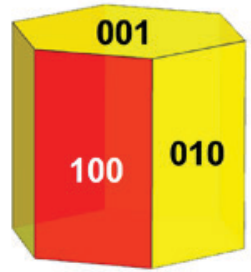

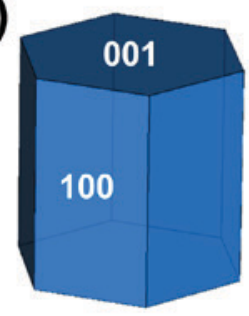

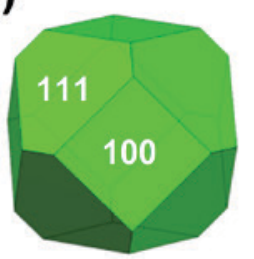

(c)

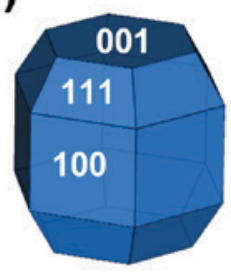

(f)

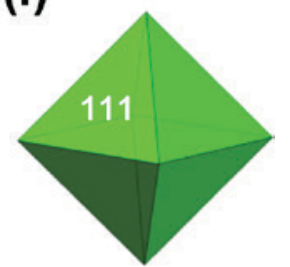

(i)

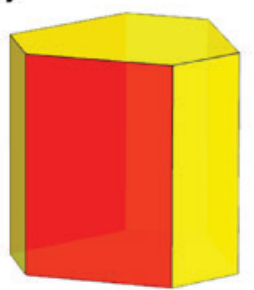

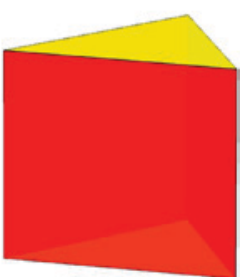

FIG. 7. Possible crystal shapes of single crystals of (a)-(c) ice $I_{h}$, (d)-(f) ice $I_{c}$, and (g)-(i) ice $I_{\text {sd }}$. The Miller indices (hkl) of some of the faces are indicated. The shapes (g)-(i) can have varying axial ratios, forming needles or plates.

The extinction and absorption efficiencies are shown in Fig. 9a. The results show that the extinction varies in the well-known oscillatory manner that is in keeping with the interference of the diffracted and transmitted waves. The optical properties of individual particles are presented here and, if they were integrated over a size distribution of particles, then the oscillatory behavior would tend to cancel out. The absorption efficiency, however, is consistently lower for trigonal and scalene shapes compared to the hexagonal shaped crystals. As the shape progresses away from the triangular shape into the scalene regime, the absorption tends to that expected for hexagonal columns.

Also, the single-scattering albedo, which is one of the often-used inputs in radiative transfer solutions (e.g., Dobbie et al. 1999), is shown in Fig. 9b. The results show that for a range of sizes the singlescattering albedo is significantly higher for trigonal columns-by as much as about $20 \%$.

These preliminary results are only indicators of the different optical properties between hexagonal and trigonal ice crystals. A more rigorous approach would include other effects such as internal reflection and refraction, photon tunneling, and edge diffraction, which can be addressed by methods described by Mitchell et al. (2006). Also, the angular distribution of scattered light described by the asymmetry would be an additional parameter that would be very useful to assess by other methods and would likely have an important effect. In 
any more thorough treatment, there are a number of factors to consider such as the orientation of the particles relative to the incident solar angle, a complete treatment of complex refractive index across the solar and IR spectrums, size distributions (potentially multimodal and orientation dependent) of different scalene particles, and relative proportions of different ice particle shapes. However, this work does indicate that there are significant differences between trigonal and hexagonal crystals; hence, this research should be explored and a more complete assessment performed.

SUMMARY AND CONCLUSIONS. For many years it has generally been assumed that ice crystals in much of Earth's troposphere were composed primarily of ice $I_{h}$. However, recent crystallographic work on the structure of ice has shown that ice crystals contain stacking disorder more often than previously thought (Hansen et al. 2008a; Kuhs et al. 2012; Malkin et al. 2012, 2015). Stacking disorder (e.g., introduction of cubic sequences into a hexagonal structure) leads to crystal shapes with threefold rotational symmetry. Hence, the occurrence of crystals with threefold symmetry over a wide range of atmospheric and laboratory conditions is consistent with the presence of stacking-disordered ice.

Since stacking-disordered ice is metastable, it will relax in time to leave ice $I_{h}$. The time required for this process depends on temperature (Hansen et al. 2008b; Kuhs et al. 2012; Murray and Bertram 2006), with faster rates at higher temperatures. Hence, we might expect trigonal crystals to be more common at lower temperatures. While there is some evidence for this, as suggested by the observations of Heymsfield (1986), who reported that $50 \%$ of crystals in the very cold TTL on one campaign were trigonal, the temperature dependence is not straightforward at higher temperatures (Yamashita 1973).

Since the lifetime of stacking disorder is longer at low temperatures (Murphy 2003), it might be expected that cold ice clouds in Earth's troposphere, stratosphere, and mesosphere or those of other planets could be dominated by trigonal ice crystals. Noctilucent clouds in Earth's high-latitude upper mesosphere form at temperatures below $150 \mathrm{~K}$ (Rapp and Thomas 2006) and it has been suggested that they are composed of cubic ice (Murray and Plane 2003a,b, 2005; Murray and Jensen 2010 ). More recent work suggests this ice is more likely stacking disordered (Kuhs et al. 2012; Malkin et al. 2012; Murray et al. 2015), which might form trigonal crystals. Trigonal ice crystals might be important in type-II polar stratospheric clouds (PSCs), which only form below about $188 \mathrm{~K}$ (Lowe and MacKenzie 2008), and water ice clouds, which form in the Martian atmosphere at
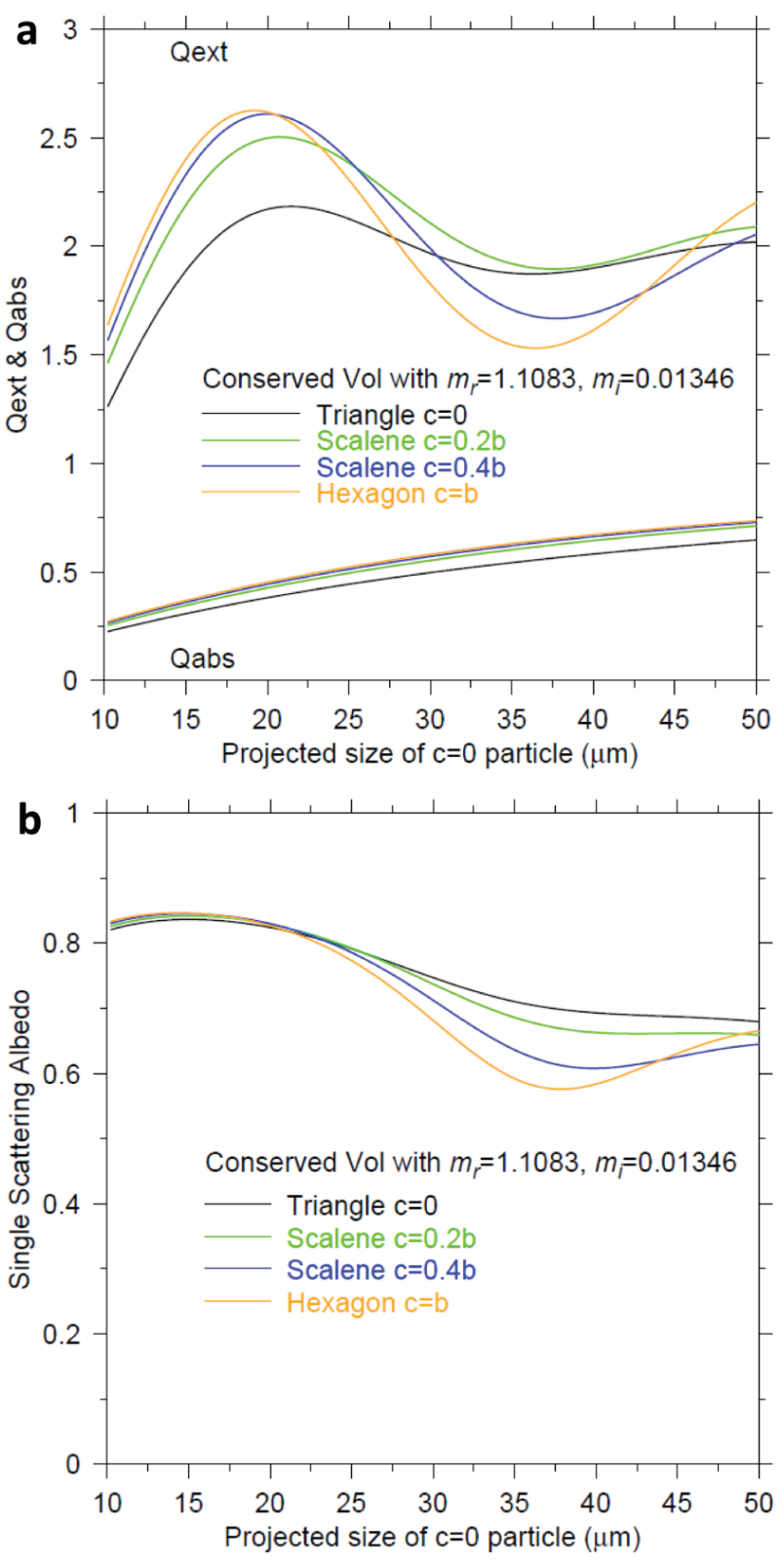

FIG. 9. Estimated radiative properties of column ice crystals for particles ranging in size from 10 to $50 \mu \mathrm{m}$ and with basal faces ranging from triangular to hexagonal. The lengths of the two groups of alternating prismatic faces are expressed $a s b$ and $c$ so that $a$ crystal with a triangular basal face is $c=0$ and for $a$ hexagonal basal face $b=c$ (see supplemental information). (a) The extinction and absorption efficiencies and (b) the corresponding single-scattering albedos. The projected size is the equivalent size of a triangular crystal of conserved volume.

temperatures below $200 \mathrm{~K}$ (Cziczo et al. 2013). Given the importance of crystal structure in determining the shape, radiative, and other properties of atmospheric ice crystals on Earth and elsewhere, the role of stacking disorder in ice should become a focus of future research 
in the atmospheric community. In particular, we recommend new measurements of ice crystal shapes in the very cold tropical tropopause layer-a region of the atmosphere important for both climate and transport into the stratosphere and where we expect stacking disorder to persist and crystals to be trigonal.

ACKNOWLEDGMENTS. Murray acknowledges the European Research Council (FP7, 240449 ICE) and the Natural Environment Research Council (NE/K004417/1, NE/I020059/1, NE/I013466/1) for funding. Salzmann thanks the Royal Society for a University Research Fellowship (UF100144). Neely was funded by the Advanced Study Program at the National Center for Atmospheric Research. Cox received funding through the CIRES Visiting Fellows program. The crystals in Fig. 2 were collected as part of the Integrated Characterization of Energy, Clouds, Atmospheric State and Precipitation at Summit (ICECAPS) project as part of the U.S. Arctic Observing Network (AON) (Shupe et al. 2013) and associated meteorology is supported by the NOAA/Earth System Research Laboratory (ESRL). The photo credit for Fig. 8 is Ed Stockard.

\section{REFERENCES}

Ball, P., 2011: In retrospect: On the six-cornered snowflake. Nature, 480, 455-455, doi:10.1038/480455a.

Bentley, W. A., and W. J. Humphreys, 1962: Snow Crystals. Dover Publications, $226 \mathrm{pp}$.

Cziczo, D. J., and Coauthors, 2013: Ice nucleation by surrogates of Martian mineral dust: What can we learn about Mars without leaving Earth? J. Geophys. Res. Planets, 118, 1945-1954, doi:10.1002/jgre.20155.

Dent Glasser, L. S., 1984: Symmetry. University College Cardiff Press for the International Union of Crystallography, $20 \mathrm{pp}$.

Dobbie, J. S., J. N. Li, and P. Chylek, 1999: Two- and four-stream optical properties for water clouds and solar wavelengths. J. Geophys. Res., 104, 2067-2079, doi:10.1029/1998JD200039.

Goodman, J., O. B. Toon, R. F. Pueschel, K. G. Snetsinger, and S. Verma, 1989: Antarctic stratospheric ice crystals. J. Geophys. Res., 94, 16 449-16 457, doi:10.1029/JD094iD14p16449.

Hallett, J., W. P. Arnott, M. P. Bailey, and J. T. Hallett, 2002: Ice crystals in cirrus. Cirrus, D. K. Lynch et al., Eds., Oxford University Press, 41-77.

Hansen, T. C., M. M. Koza, and W. F. Kuhs, 2008a: Formation and annealing of cubic ice: I. Modelling of stacking faults. J. Phys.: Condens. Matter, 20, 285104, doi:10.1088/0953-8984/20/28/285104.

,-- , P. Lindner, and W. F. Kuhs, 2008b: Formation and annealing of cubic ice: II. Kinetic study. J.
Phys.: Condens. Matter, 20, 285105, doi:10.1088/09538984/20/28/285105.

Havemann, S., and A. J. Baran, 2001: Extension of Tmatrix to scattering of electromagnetic plane waves by non-axisymmetric dielectric particles: Application to hexagonal ice cylinders. J. Quant. Spectrosc. Radiat. Transfer, 70, 139-158, doi:10.1016/S0022 -4073(00)00127-8.

Heymsfield, A. J., 1986: Ice particles observed in a cirriform cloud at $-83^{\circ} \mathrm{C}$ and implications for polar stratospheric clouds. J. Atmos. Sci., 43, 851-855, doi:10.1175/1520 -0469(1986)043<0851:IPOIAC>2.0.CO;2.

Hobbs, P. V., 1974: Ice Physics. Clarendon Press, 837 pp. Jensen, E. J., and Coauthors, 2013: Ice nucleation and dehydration in the Tropical Tropopause Layer. Proc. Natl. Acad. Sci. USA, 110, 2041-2046, doi:10.1073 /pnas.1217104110.

Kepler, J., 2010: The Six-Cornered Snowflake: A New Year's Gift. Paul Dry Books, 115 pp.

Kikuchi, K., and A. W. Hogan, 1979: Properties of diamond dust type ice crystals observed in summer season at Amundsen-Scott South Pole Station, Antarctica. J. Meteor. Soc. Japan, 57, 180-190.

Korolev, A. V., G. A. Isaac, and J. Hallett, 1999: Ice particle habits in Arctic clouds. Geophys. Res. Lett., 26, 1299-1302, doi:10.1029/1999GL900232.

Kuhs, W. F., D. V. Bliss, and J. L. Finney, 1987: Highresolution neutron powder diffraction study of ice I. J. Phys. Colloq., 48, 631-636, doi:10.1051 /jphyscol:1987187.

- C. Sippel, A. Falenty, and T. C. Hansen, 2012: Extent and relevance of stacking disorder in "ice I." Proc. Natl. Acad. Sci. USA, 109, 21 259-21 264, doi:10.1073/pnas.1210331110.

Lawson, R. P., B. Pilson, B. Baker, Q. Mo, E. Jensen, L. Pfister, and P. Bui, 2008: Aircraft measurements of microphysical properties of subvisible cirrus in the tropical tropopause layer. Atmos. Chem. Phys., 8, 1609-1620, doi:10.5194/acp-8-1609-2008.

Libbrecht, K., 2006: Ken Libbrecht's Field Guide to Snowflakes. Voyageur Press, $112 \mathrm{pp}$.

—, 2008: Snowflakes. Voyageur Press, 512 pp.

— bility and the growth of triangular snow crystals. [Available online at http://arxiv.org/abs/0911.4267.]

Lowe, D., and A. R. MacKenzie, 2008: Polar stratospheric cloud microphysics and chemistry. $J$. Atmos. Sol.-Terr. Phys., 70, 13-40, doi:10.1016/j .jastp.2007.09.011.

Malkin, T. L., B. J. Murray, A. V. Brukhno, J. Anwar, and C. G. Salzmann, 2012: Structure of ice crystallized from supercooled water. Proc. Natl. Acad. Sci. USA, 109, 1041-1045, doi:10.1073/pnas.1113059109. 
,-- _ C. G. Salzmann, V. Molinero, S. J. Pickering, and T. F. Whale, 2015: Stacking disorder in ice I. Phys. Chem. Chem. Phys., 17, 60-76, doi:10.1039 /C4CP02893G.

McKnight, C. V., and J. Hallett, 1978: X-ray topographic studies of dislocations in vapour-grown ice crystals. J. Glaciol., 21, 397-407.

Mishchenko, M. I., L. D. Travis, and D. W. Mackowski, 1996: T-matrix computations of light scattering by nonspherical particles: A review. J. Quant. Spectrosc. Radiat. Transfer, 55, 535-575, doi:10.1016/0022 -4073(96)00002-7.

Mitchell, D. L., A. J. Baran, W. P. Arnott, and C. Schmitt, 2006: Testing and comparing the modified anomalous diffraction approximation. J. Atmos. Sci., 63, 2948-2962, doi:10.1175/JAS3775.1.

Mizuno, Y., 1978: Studies of crystal imperfections in ice with reference to the growth process by the use of X-ray diffraction topography and divergent Laue method. J. Glaciol., 21, 409-418.

Murphy, D. M., 2003: Dehydration in cold clouds is enhanced by a transition from cubic to hexagonal ice. Geophys. Res. Lett., 30, 2230, doi:10.1029/2003GL018566.

Murray, B. J., and J. M. C. Plane, 2003a: The uptake of atomic oxygen on ice films: Implications for noctilucent clouds. Phys. Chem. Chem. Phys., 5, 4129-4138, doi:10.1039/b305555h.

$\longrightarrow$, and — 2003b: Atomic oxygen depletion in the vicinity of noctilucent clouds. Adv. Space Res., 31, 2075-2084, doi:10.1016/S0273-1177(03)00231-X.

$\ldots$, and _ 2005: Uptake of $\mathrm{Fe}, \mathrm{Na}$ and $\mathrm{K}$ atoms on low-temperature ice: Implications for metal atom scavenging in the vicinity of polar mesospheric clouds. Phys. Chem. Chem. Phys., 7, 3970-3979, doi:10.1039/b508846a.

— , and A. K. Bertram, 2006: Formation and stability of cubic ice in water droplets. Phys. Chem. Chem. Phys., 8, 186-192, doi:10.1039/b513480c.

— of amorphous solid water particles in the upper mesosphere. J. Atmos. Sol.-Terr. Phys., 72, 51-61, doi:10.1016/j.jastp.2009.10.007.

—, D. A. Knopf, and A. K. Bertram, 2005: The formation of cubic ice under conditions relevant to Earth's atmosphere. Nature, 434, 202-205, doi:10.1038/nature03403.

—, T. L. Malkin, and C. G. Salzmann, 2015: The crystal structure of ice under mesospheric conditions. J. Atmos. Sol.-Terr. Phys., 127, 78-82, doi:10.1016/j.jastp.2014.12.005.

Peter, T., C. Marcolli, P. Spichtinger, T. Corti, M. B. Baker, and T. Koop, 2006: When dry air is too humid. Science, 314, 1399, doi:10.1126/science.1135199.
Pruppacher, H. R., and J. D. Klett, 1997: Microphysics of Clouds and Precipitation. 2nd ed. Kluwer Academic Publishers, 976 pp.

Rapp, M., and G. E. Thomas, 2006: Modeling the microphysics of mesospheric ice particles: Assessment of current capabilities and basic sensitivities. J. Atmos. Sol.-Terr. Phys., 68, 715-744, doi:10.1016/j .jastp.2005.10.015.

Sassen, K., and Y. Takano, 2000: Parry arc: A polar lidar, ray-tracing, and aircraft case study. Appl. Opt., 39, 6738-6745, doi:10.1364/AO.39.006738.

—, W. P. Arnott, D. O. Starr, G. G. Mace, Z. Wang, and M. R. Poellot, 2003: Midlatitude cirrus clouds derived from Hurricane Nora: A case study with implications for ice crystal nucleation and shape. J. Atmos. Sci., 60, 873-891, doi:10.1175/1520-0469(2003)060<0873:MC $\mathrm{CDFH}>2.0 . \mathrm{CO} ; 2$.

Satow, K., 1983: Observation on the shapes of snow crystals in the summer season in Mizuho Plateau, Antarctica. Mem. Natl. Inst. Polar Res., 29, 103-109.

Shupe, M. D., and Coauthors, 2013: High and dry: New observations of tropospheric and cloud properties above the Greenland Ice Sheet. Bull. Amer. Meteor. Soc., 94, 169-186, doi:10.1175/BAMS-D-11-00249.1.

Stokes, H. T., and D. M. Hatch, 2005: FINDSYM: Program for identifying the space-group symmetry of a crystal. J. Appl. Crystallogr., 38, 237-238, doi:10.1107 /S0021889804031528.

Sun, W. B., Q. Fu, and Z. Z. Chen, 1999: Finite-difference time-domain solution of light scattering by dielectric particles with a perfectly matched layer absorbing boundary condition. Appl. Opt., 38, 3141-3151, doi:10.1364/AO.38.003141.

Tape, W., 1994: Atmospheric Halos. Antarctic Research Series, Vol. 64, Amer. Geophys. Union, 144 pp.

- , and J. Moilanen, 2006: Atmospheric Halos and the Search for Angle x. Antarctic Research Series, Vol. 58, Amer. Geophys. Union, 238 pp.

van de Hulst, H. C., 1957: Light Scattering by Small Particles. Wiley, 544 pp.

Westbrook, C. D., 2011: Origin of the Parry arc. Quart. J. Roy. Meteor. Soc., 137, 538-543, doi:10.1002 /qj.761.

Wood, S. E., M. B. Baker, and D. Calhoun, 2001: New model for the vapor growth of hexagonal ice crystals in the atmosphere. J. Geophys. Res., 106, 4845-4870, doi:10.1029/2000JD900338.

Yamashita, A., 1969: Uncommon ice crystals observed in a large cold room. J. Meteor. Soc. Japan, 47, 57-58.

_ 1971: Skeleton ice crystals of non-hexagonal shape grown in free fall. J. Meteor. Soc. Japan, 49, 215-231.

- 1973: On the trigonal growth of ice crystals. $J$. Meteor. Soc. Japan, 51, 307-317. 
AMS titles now

avallable as eBooks

at springer.com

\section{AMS BOOKS}

\section{RESEARCH APPLICATIONS HISTORY}

www.ametsoc.org/amsbookstore

Springer

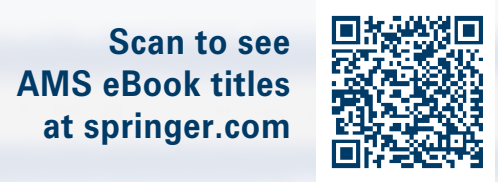

2) Springer

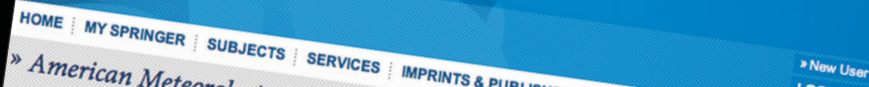

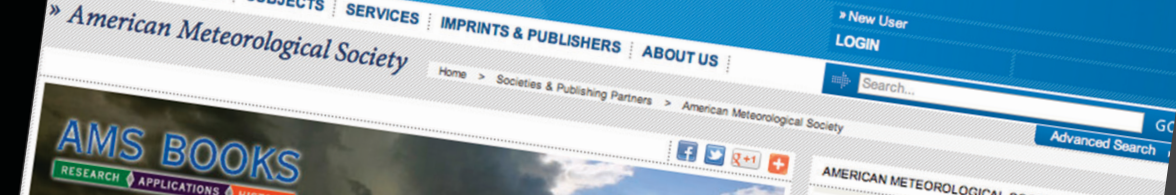

